\title{
ARTICLES
}

\section{Mode of Delivery and Asthma - Is There a Connection?}

\author{
JUKKA KERO, MIKA GISSLER, MINNA-MAIJA GRÖNLUND, PENTTI KERO, \\ PERTTI KOSKINEN, ELINA HEMMINKI, AND ERIKA ISOLAURI \\ Department of Paediatrics (J.K., M-M.G., P. Kero, E.I.), Department of Clinical Chemistry (P. Koskinen), \\ Turku University Central Hospital, FIN-20520, Turku, Finland and the National Research and \\ Development Centre for Welfare and Health (M.G., E.H.), FIN-00531, Helsinki, Finland
}

\begin{abstract}
Genetic factors cannot explain the recent rapid increase in the incidence of atopic diseases. The phenomenon has been explained by environmental factors, and there are data for and against the hypothesis that a decline in the pressure of microbial stimulation early in life could be behind the allergy epidemic. Changes have also occurred in maternity care, among them a rise in the caesarean section rate, which could diminish initial microbial exposure and thereby alter $\mathrm{T}$ helper 1 cell/T helper- 2 cell development and affect the risk of developing atopy. In this study, we sought to establish whether mode of delivery does influence the development of atopic asthma. Finnish 1987 Medical Birth Register ( $n=59,927$ live births) information was linked between several national health registers to obtain information on asthma and mode of delivery in children registered. The data were adjusted for maternal age, previous deliveries, child's sex, and birth size. Atopy was evaluated in the second study (Turku Birth Cohort), which involved 219 children born by vaginal delivery $(n=106)$ or caesarean section $(n=113)$; history of atopic symptoms was established by questionnaire and a clinical examination was conducted, including skin prick testing and determination of total and allergen-specific $\operatorname{IgE}$ in serum.
\end{abstract}

\section{ABSTRACT}

The register study showed the cumulative incidence of asthma at the age of seven to be significantly higher in children born by caesarean section $(4.2 \%)$ than in those vaginally delivered $(3.3 \%)$, the adjusted odds ratio (OR) for confounding variables being $1.21(1.08-1.36), p<0.01$. In the second study, significantly more positive allergy tests were reported in questionnaires in the caesarean $(22 \%)$ than in the vaginal delivery group (11\%), OR $2.22(1.06-4.64), p<0.01$, and a trend toward more positive skin prick reactions was documented at clinical examination; $41 \%$ versus $29 \%$, OR $1.31(0.65-2.65), p=0.11$. In conclusion, these results suggest that caesarean section delivery may be associated with an increased prevalence of atopic asthma. (Pediatr Res 52: 6-11, 2002)
OR, odds ratio
HEP, histamine equivalent in prick testing
Th1/Th2, T helper type 1 cell/T helper type 2 cell
ICD, International Classification of Diseases (book)
TGF- $\boldsymbol{\beta}$, Transforming growth factor $\beta$

Abbreviations
During the past two decades the incidence of asthma and other atopic diseases has increased in industrialized countries (1-7). Notwithstanding the marked hereditary element in atopy, this rapid increase may well be attributable to changes in environmental factors, and in this context it is of note that the rate of caesarean section deliveries has more than doubled during the past $20 \mathrm{y}$ and this trend seems to continue $(8-10)$.

November 29, 2000; June 26, 2001.

Correspondence and reprint requests: Jukka Kero M.D., Pharmakologisches Institut, Ruprecht-Karls-Universität Heidelberg, Im Neuenheimer Feld 366/Room 309, Heidelberg D-69120, Germany; e-mail: Jukka.Kero@urz.uni-heidelberg.de

This study was supported by the Paediatric Research Foundation.

DOI: 10.1023/01.PDR.0000017262.01840.F0
The question addressed here was, whether the mode of delivery could be one influencing factor in development of asthma and atopy?

Hypothesis for the study came from the findings that caesarean section deliveries interfere with a wide range of physiologic and immunologic factors: establishment of normal intestinal microflora is delayed $(11,12)$, number of fetal neutrophils and natural killer cells is decreased $(13,14)$ and activity of phagocytic function is increased, and these modifications may exert their effects beyond the immediate postnatal period (15). For the rise in atopic diseases the factors modulating the immunologic system early in life may be essential. The exposure of microbes may alter $\mathrm{T}$ helper 1 cell/T helper- 2 
cell development and thereby affect the risk of developing atopy (16-18). Intestinal microflora play a crucial role in oral tolerance induction; specific strains of the gut microflora have been shown to stimulate the production of anti-inflammatory cytokines like IL-10 and TGF- $\beta$, which could counteract T helper 2 -phenotype prominent in atopy $(19,20)$, while lack of intestinal microflora leads to sustained T helper 2- type responsiveness, which supports B cell IgE production (21). Therefore, it is suggested that early and constant stimulation by the gut microflora, which is the first major source of microbial stimulus, could be more important than that of occasional infection.

The objective of the present study was to assess the impact, if any, of the mode of delivery on the prevalence of atopic asthma. To address this issue, we first used Finnish Medical Birth Register information obtained from follow-up of the whole 1987 birth cohort ( $\mathrm{n}=59927$ live births). The register was linked with several national health registers to obtain information on asthma to the age of seven years. Second, a cohort of 219 children born in Turku, Finland in 1990 by vaginal delivery $(n=106)$ and by caesarean section $(n=113)$ were studied for the prevalence of atopy by questionnaire, clinical examination, skin prick-testing and determination of serum total and allergen-specific IgE.

\section{METHODS}

\section{The Finnish Birth Cohort}

Design. To evaluate the incidence of asthma in children born by vaginal delivery or caesarean section a cohort was formed from the 1987 Finnish Medical Birth Register, which covered 59927 live births, of whom $99.9 \%$ were identified in the follow-up. Follow-up data from birth to seven years of age were collected from three national registers after general permission for the data linkage was received from the national data protection authorities. The quality of the registers (22) as well as of the data collection methods have been shown to be satisfactory or good, as described in detail elsewhere $(23,24)$. Data on children who had permanently emigrated from Finland ( $n=287)$ or died ( $n=440$, including 193 neonatal deaths) were included in the analysis until the event. Diagnosis codes for asthma came from Hospital Discharge Register, Statistical Database for Care Support and from Statistical Database for Preferential Refunded Medicines as earlier described (25). Cumulative incidence of asthma was collected from register records, coded according to the classification of International Classification of Diseases (ICD-9) diagnosis codes (26), used in Finland from 1987 to 1995, which covers the whole study period. Bronchial asthma, ICD-9 code 493, corresponds to ICD-10 codes J45-J46.

\section{The Turku Birth Cohort}

Design. To evaluate the prevalence of atopy between the two modes of delivery a Turku Birth cohort was done. In 1990 there were 2964 deliveries in Turku University Hospital, of which 463 were by caesarean section (15.6\%). A randomly selected cohort of 164 mothers who had given birth by caesarean section was selected (Fig. 1) by a nurse who was unaware of the study design. The criteria for selection were that the child was full term and was not treated in the intensive care unit. A control group of 164 mothers fulfilling the same criteria, who had delivered vaginally were individually matched for gestational age with $7 \mathrm{~d}$ accuracy. With this estimated number of individuals an increase of $15 \%$ in the frequency of atopy between the two delivery groups could be detected at $5 \%$ level of significance $(80 \%$ power); minimum recruitment was 65 per group to detect the difference at $70 \%$ power.

A questionnaire, asked to be filled by the parents, concerning symptoms of atopic diseases was sent to the families, who fulfilled the additional criteria on that the child, born in 1990, had started school in Turku, i.e. the family lived in the hospital area. On this basis, nine children were excluded from the study (Fig. 1). This information, as well as addresses, was obtained from Central Population Register. The questionnaire was sent again to nonresponders. Finally, those 219 (69\%) who had responded were requested to attend for clinical examination, skin prick testing and determination of serum total and antigenspecific IgE antibodies. In these cases, perinatal factors were evaluated from the hospital medical records. The questionnaire and clinical examination were done from January 1 through January 11, 1998.

For all study subjects, written informed consent was obtained from the parents. The study was approved by the university joint Committee on Ethics and Turku University Central Hospital.

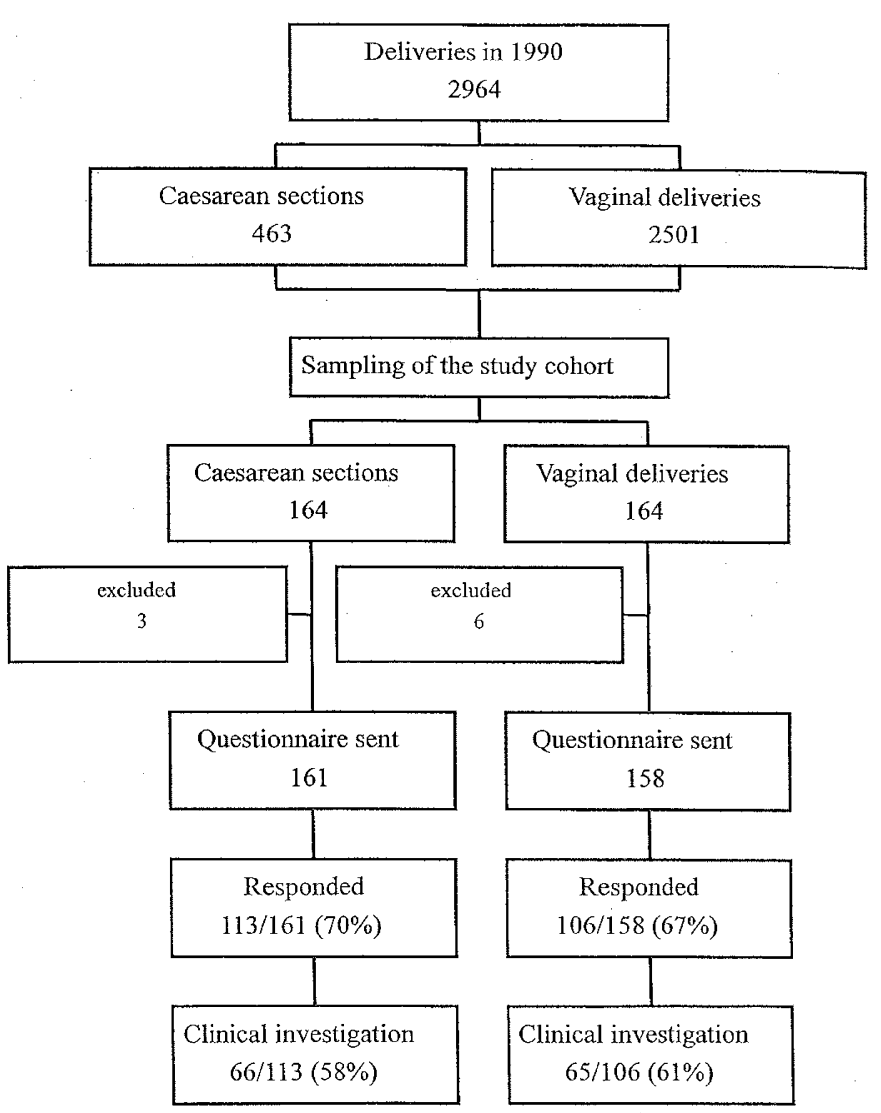

Figure 1. Profile of the Turku Birth Cohort study. 
The questionnaire. The questionnaire concerned present and previous atopic symptoms in the child and the family; questions were adapted from the ISAAC study (27). For the study subjects, children born in 1990, information was obtained on previous symptoms of atopic eczema, allergic rhinitis, allergic conjunctivitis or asthma. The age of these symptoms and aggravating factors, and whether or not any allergy tests for these symptoms had been positive were also asked. Similar questions were addressed to first-degree family members. In addition, questions were included on parents' smoking habits, the presence of furry pets at home and the duration of breast-feeding.

Clinical examination. All subjects whose questionnaire was returned, $219 / 328(69 \%)$, were invited to participate in a clinical examination, which was made by two of the authors (J.K. and M-M.G.) with no previous information as to delivery history. Altogether 131 children participated to examination; 65 of 106 vaginal delivery and 66 of 113 caesarean group (Fig. 1). In addition to a general pediatric clinical examination, all signs and symptoms of atopic diseases were recorded. Asthma was confirmed for those children who were previously given an asthma diagnosis by a doctor, according to accepted criteria (28).

After clinical examination, data on perinatal factors were collected from hospital medical records, covering pregnancy (gravida, partus, medication during pregnancy, diagnoses during pregnancy, smoking habits, infections, increased blood pressure and proteinuria), birth and the newborn (weight, length and head circumference, Apgar scores, $\mathrm{pH}$ and medication or any treatment).

Skin-prick testing. Skin-prick testing (Soluprick, ALK, Copenhagen, Denmark) was done on the volar side of the child's lower arm with a panel of 12 common allergen extracts. These included tests for birch, cat, dog (10 histamine equivalent in prick testing (HEP)), Dermatophagoides pteronyssimus (10 HEP), grass mix, including timothy grass (Phleum pratense), Dactylis glomerata, Poa pratensis, Alopecurus pratensis, Lolium perenne (all 10 HEP), cow's milk (fat-free, standard foodstuff), potato (standard foodstuff), carrot and hen's-egg white (standard foodstuff), wheat (10\% wt/vol in saline), fish $(1 / 20)$ and gliadin $(1 \mathrm{mg} / \mathrm{mL})$. Histamine chloride $(10 \mathrm{mg} / \mathrm{mL})$ served as a positive control and allergen extract diluent as a negative. A skin test was regarded as positive if the diameter of the allergen weal (minus the reaction to negative control) was at least $3 \mathrm{~mm}$ or the ratio of the allergen weal diameter to the diameter of the histamine weal was at least 0.5 . The perpendicular diameters of each weal were recorded after $15 \mathrm{~min}$. The same batches of each extract were used, and testing was done throughout the study by the same nurse, who was unaware of delivery status.

Serum analysis. A blood sample was taken from each child. The blood was centrifuged and serum separated and stored at $-20^{\circ} \mathrm{C}$ until analysis. Levels of allergen specific IgE antibodies in serum were determined with Pharmacia CAPTM RAST $^{\circledR}$ RIA (Pharmacia and Upjohn, Uppsala, Sweden) according to manufacturer's instructions. Analyses were done using two mixtures of allergens, one comprising 11 airway allergens (Phadiatop) and one comprising six food allergens (Code $f * 5$ ).
Higher than $0.35 \mathrm{kU} / \mathrm{L}$ IgE value, in Phadiatop or in $\mathrm{f} \times 5$ tests, were considered as positive.

Statistical analysis. In the questionnaire and the clinical study, data were analyzed by $\chi^{2}$-and t-tests. Significance was set at $p<0.05$. In the register study, odds ratios (OR) with $95 \%$ confidence intervals (CI) were calculated for differences between the modes of delivery groups, using the vaginal delivery group as reference group. The OR for asthma, allergic rhinitis and atopic eczema in children born by caesarean section were adjusted by potentially confounding factors, which have been found to be common risk factors for atopic disease: maternal age (continuous), previous deliveries $(0,1,2$, $3,4+$ ), child's sex and birth weight (continuous).

\section{RESULTS}

\section{The Finnish Birth cohort}

Demographic characteristics of the study population. There were several explanatory factors associated with caesarean section delivery. The older the mother, the smaller the parity, the lower the birth weight of the child, and whether the sex was male (confounding factors) determined the likelihood of caesarean section delivery as being higher. In contrast, it was not related to social class or smoking during pregnancy (data not shown). The confounding factors were taken into account when evaluating the risk of atopic disease in children born by vaginal delivery or by caesarean section.

Cumulative incidence of asthma in children born by vaginal delivery or caesarean section. The cumulative incidence of asthma at the age of seven years was significantly higher in children born by caesarean section $366 / 8826(4.2 \%)$ than in those vaginally delivered $1684 / 51039$ (3.3\%), OR 1.27 (1.13$1.42), p<0.001$. After adjusting for possible confounding variables, the OR for asthma was $1.21(1.08-1.36), p<0.001$. Differences in birth weight distribution explained $22 \%$ of the higher asthma prevalence in the caesarean section group.

\section{The Turku Birth Cohort}

Demographic characteristics of the study population. The groups of children delivered vaginally or by caesarean section that responded to the questionnaire were similar with respect to other information on pregnancy and birth. There were no

Table 1. The Turku Birth Cohort study

\begin{tabular}{lcc}
\hline & Vaginal delivery group & Caesarean section group \\
\hline Breast-fed (months) $\dagger$ & $7.7(4.5)$ & $6.4(4.2)^{*}$ \\
$\geq 4$ months & $83 / 106(78 \%)$ & $74 / 112(67 \%)^{* *}$ \\
Home environment & & \\
Smokers in family & $32 / 100(32 \%)$ & $37 / 110(34 \%)$ \\
furred pets at home & $45 / 106(42 \%)$ & $43 / 113(38 \%)$ \\
Family history of asthma & & \\
Mother & $8 / 106(8 \%)$ & $8 / 112(7 \%)$ \\
Father & $5 / 105(5 \%)$ & $10 / 107(9 \%)$ \\
Siblings & $9 / 99(9 \%)$ & $13 / 99(13 \%)$ \\
\hline
\end{tabular}

Demographic data on mothers and their children, born by vaginal delivery or caesarean section, who responded to the questionnaire.

$\dagger$ Mean (SD), $* p=0.029, * * p=0.04, \chi^{2}$-test. Other differences were not statistically significant. 
differences in the number of children in the family (data not shown) or other factors currently considered to entail a risk of atopic disease e.g. smoking, furry pets at home or family history of atopy (Table 1). However, in the vaginally delivered group the duration of breast-feeding was significantly longer than in the caesarean group (Table 1). The rate of response to the questionnaire was similar in the vaginal delivery and caesarean section groups, 106/158 (67\%) and 113/161 (70\%), respectively (Fig. 1). Those responding were requested to attend for clinical examination, and $65 / 106(61 \%)$ of the vaginal delivery group and 66/113 (58\%) of the caesarean group participated (Fig. 1).

Prevalence of atopy and asthma in children born by vaginal delivery or caesarean section in the questionnaire and clinical examination. According to the questionnaires, significantly more positive allergy tests were reported by the caesarean section group, $25 / 113(22 \%)$ as against $12 / 106(11 \%)$ in the vaginally delivered children, OR 2.22 (1.06-4.64), $p<$ 0.01 . Testing was more likely to have been performed, if the family reported atopic symptoms in the child (48\%), compared with those who did not (5\%). Also children born by caesarean section were reported to have more often asthma, 16/113 (14.2\%) versus $10 / 106(9.4 \%), p=0.28$ compared with vaginally delivered children. Symptoms of asthma were most frequently associated with pollens and animals.

In like manner, in clinical examination, skin prick tests were found positive more frequently in the caesarean section group $24 / 66(41 \%)$ than in the vaginal delivery group $18 / 65(29 \%)$, OR $1.31(0.65-2.65), p=0.11$. The allergens causing skin test reactivity most commonly were pollen from grass mix, birch and animals (data not shown). The diagnosis of asthma, confirmed earlier by the doctor according to the accepted criteria (28), was found in 4 children (6\%) of vaginally delivered and in 8 children $(12 \%)$ born by section $(p=0.24)$.

Blood samples were available from 126/131 children. Total $\mathrm{IgE}$ antibody concentrations and specific IgE antibodies against common allergens did not differ significantly between the two groups (data not shown). As expected, children who were reported to have symptoms of atopic disease were more likely to participate in the clinical examination, although there was no difference in the participation rate between the two delivery groups.

\section{DISCUSSION}

The results of the present study suggest that children born by caesarean section have increased risk of asthma and atopy. We combined two methods, evaluation of registers and questionnaire and clinical examination, of which both have their merits and disadvantages. A register study including complete data on one birth year cohort has no selection bias, while clinical examination of a selected but controlled cohort allowed objective testing of atopy. As the results of both studies were in same direction, it would seem justifiable to suggest that there is a critical period early in life when the atopic phenotype may be amenable to counter-regulatory processes and that factor(s) associated with caesarean section may not support these processes.
The Turku cohort study, designed to evaluate the prevalence of atopy, showed comparable rate of positive skin prick tests to those of previous studies (29). Therefore it was interesting to note that according to the questionnaire significantly more skin-prick tests or other allergy tests for atopic symptoms had been performed in children born by caesarean section than in vaginally delivered. In the clinical study, evaluating the phenomenon at the age of seven years, a trend was seen. It is possible that small sample size of the study could have precluded detection of statistically significant differences. Our explanation for this difference may arise from the natural course of food allergies: prevalent in early infancy and outgrown by school age. On the other hand, the result of skin prick test and IgE antibody measurement were not fully concordant with the specific diagnoses, which is in line with earlier reports in this age group (30), as also the finding of serum specific $\operatorname{IgE}$ antibodies showing lower sensitivity compared with skin prick tests $(31,32)$.

In the Finnish Birth Cohort study, designed to detect the association between asthma and mode of delivery, the incidence of asthma was comparable to that of earlier reports in Finland (33) and elsewhere $(34,35)$. These results again showed that children born by caesarean section had more asthma and positive skin prick tests than those born by normal vaginal delivery. Our results also confirm the previously reported good feasibility of register-based follow-up $(22,24)$. The main concern in register-based research is the quality of used data sources. In this study, especially the correctness of diagnoses is essential. The diagnoses were based on hospitalization data and on social benefits. The data on hospitalization have been reported to be satisfactory or even good (36). Furthermore, the common care practice is to avoid hospitalization of young children, which causes that only severe cases are treated in hospitals. Social benefits are given for severe cases only, and the decisions to receive these benefits are based on clinical examination made by physicians. All the decisions are reviewed by the experts at the Social Insurance Institution, which decreased the possibilities to incorrect or misleading information.

What then could be the explanation for the increased prevalence of asthma and atopy in children born by caesarean section? We do not think that this is due simply to a selection bias in that mothers delivering by caesarean section have more allergies themselves. Although there are studies demonstrating a higher rate of caesarean section in asthmatic mothers (37), in the questionnaire study the two delivery groups were similar in respect of allergic symptoms in the mothers and other family members. Another selection bias could have arisen from differences in the social class. Some previous studies have shown a higher prevalence of asthma in the upper social class $(38,39)$. In the register study, no significant difference between social classes was observed in the caesarean section rate or in the cumulative incidence of asthma. Low birth weight has been associated with an increasing risk of asthma (40). Based on our data, this may be due to an association with the mode of delivery, as caesarean section carried a greater risk of asthma than birth weight per se; after adjusting with birth weight, only one-fifth reduction in the risk of asthma was seen. Moreover, in 
the Turku Birth Cohort study the birth weight and head circumference of the children in the caesarean delivery and vaginal delivery groups were indistinguishable (data not shown). However, we suggest that the mode of delivery needs to be taken into account in future research on an association between large head circumference at birth or other indications of disproportional growth and atopy (41), since disproportional growth, large size or large head circumference of the fetus may lead more often to caesarean section $(42,43)$. The small sample size of our cohort study precludes the conclusions about the head circumference and caesarean section.

A more likely explanation for the increased prevalence of atopic disease in the caesarean section group could derive from the distinct immunologic effects exerted by the two modes of delivery. Normal vaginal delivery is a stressful process thought to be beneficial for the child's health in promoting lung function and maturation of the immune system (13). Distinct effects on breast-feeding also provide notion, as it not only offers optimal nutrition but also supports the proper maturation of gut barrier function through provision of growth factors and immunologically active cells and mediators. Although the questionnaire study revealed a shorter duration of breast-feeding in the caesarean section group, the mean duration in both groups exceeded $6 \mathrm{mo}$, and the difference detected is unlikely to influence atopy later in life $(44,45)$.

A major regulatory factor in the developing immune system is the gut microflora. Interestingly, differences in intestinal microflora have been found between atopic and nonatopic children (46), and such differences may even precede the development of atopy (47). On the other hand, caesarean section is associated with delayed intestinal colonization (11), which could deprive the newborn of the immunostimulatory impulses at a very critical period in life when the immune system and the gut barrier maturate (48). Infants born by vaginal delivery have been shown to have higher nonspecific activity of immune system compared with infants born by caesarean section $(15,49)$. Thus caesarean section may be associated with a lack of processes like production of IL-10 (50) or TGF- $\beta$ (19), which could redirect the constitutive Th2-phenotype of the newborn to normal.

In summary, the results here show an association between caesarean section and increased prevalence of atopic asthma. Thus there may be some causality between the parallel increases in caesarean section rate and atopic disease in developed countries, which calls for better understanding of the differences between the two modes of delivery and their role in regulating the immune system of the newborn.

Acknowledgments. The authors thank Satu Ekblad, RN, and Sari Laksio, RN, for skillful assistance in selection of the groups and skin-prick testing.

\section{REFERENCES}

1. Peat JK, van den Berg RH, Green WF, Mellis CM, Leeder SR, Woolcock AJ 1994 Changing prevalence of asthma in Australian children. BMJ 308:1591-1596

2. von Mutius E, Fritzsch C, Weiland SK, Roll G, Magnussen H 1992 Prevalence of asthma and allergic disorders among children in united Germany: a descriptive comparison. BMJ 305:1395-1399
3. von Mutius E, Weiland SK, Fritzsch C, Duhme H, Keil U 1998 Increasing prevalence of hay fever and atopy among children in Leipzig, East Germany. Lancet 351:862-866

4. No authors listed 1998 Worldwide variation in prevalence of symptoms of asthma, allergic rhinoconjunctivitis, and atopic eczema: ISAAC. The International Study of Asthma and Allergies in Childhood (ISAAC) Steering Committee. Lancet 351:12251232

5. Lang DM, Polansky M 1994 Patterns of asthma mortality in Philadelphia from 1969 to 1991. N Engl J Med 331:1542-1546

6. Taylor B, Wadsworth J, Wadsworth M, Peckham C 1984 Changes in the reported prevalence of childhood eczema since the 1939-45 war. Lancet 2:1255-1257

7. Nakagomi T, Itaya H, Tominaga T, Yamaki M, Hisamatsu S, Nakagomi O 1994 Is atopy increasing? Lancet 343:121-122

8. Macfarlane A 1998 At last-maternity statistics for England. BMJ 316:566-567

9. Eskew PN, Jr., Saywell RM, Jr., Zollinger TW, Erner BK, Oser TL 1994 Trends in the frequency of cesarean delivery. A 21-year experience, 1970-1990. J Reprod Med 39:809-817

10. MacKenzie IZ 1999 Should women who elect to have caesarean sections pay for them? BMJ 318:1070

11. Grönlund MM, Lehtonen OP, Eerola E, Kero P 1999 Fecal microflora in healthy infants born by different methods of delivery: permanent changes in intestinal flora after cesarean delivery. J Pediatr Gastroenterol Nutr 28:19-25

12. Bennet R, Nord CE 1987 Development of the faecal anaerobic microflora after caesarean section and treatment with antibiotics in newborn infants. Infection 15:332-336

13. Thilaganathan B, Meher-Homji N, Nicolaides KH 1994 Labor: an immunologically beneficial process for the neonate. Am J Obstet Gynecol 171:1271-1272

14. Kinoshita Y, Masuda K, Kobayashi Y 1991 Adherence of cord blood neutrophils: effect of mode of delivery. J Pediatr 118:115-117

15. Grönlund MM, Nuutila J, Pelto L, Lilius EM, Isolauri E, Salminen S, Kero P, Lehtonen OP 1999 Mode of delivery directs the phagocyte functions of infants for the first 6 months of life. Clin Exp Immunol 116:521-526

16. Shaheen SO, Aaby P, Hall AJ, Barker DJ, Heyes CB, Shiell AE, Goudiaby A 1996 Measles and atopy in Guinea-Bissau. Lancet 347:1792-1796

17. Shirakawa T, Enomoto T, Shimazu S, Hopkin JM 1997 The inverse association between tuberculin responses and atopic disorder. Science 275:77-79

18. Matricardi PM, Rosmini F, Ferrigno L, Nisini R, Rapicetta M, Chionne P, Stroffolini T, Pasquini P, D'Amelio R 1997 Cross sectional retrospective study of prevalence of atopy among Italian military students with antibodies against hepatitis A virus. BMJ 314:999-1003

19. Hansen G, McIntire JJ, Yeung VP, Berry G, Thorbecke GJ, Chen L, DeKruyff RH, Umetsu DT 2000 CD4(+) T helper cells engineered to produce latent TGF-betal reverse allergen-induced airway hyperreactivity and inflammation. J Clin Invest 105:61-70

20. Sanfilippo L, Li CK, Seth R, Balwin TJ, Menozzi MG, Mahida YR 2000 Bacteroides fragilis enterotoxin induces the expression of IL-8 and transforming growth factorbeta (TGF-beta) by human colonic epithelial cells. Clin Exp Immunol 119:456-4563

21. Sudo N, Sawamura S, Tanaka K, Aiba Y, Kubo C, Koga Y 1997 The requirement of intestinal bacterial flora for the development of an $\operatorname{IgE}$ production system fully susceptible to oral tolerance induction. J Immunol 159:1739-1745

22. Gissler M, Teperi J, Hemminki E, Meriläinen J 1995 Data quality after restructuring a national medical registry. Scand J Soc Med 23:75-80

23. Gissler M, Jarvelin MR, Hemminki E 2000 Comparison between research data and routinely collected register data for studying childhood health. Eur J Epidemiol 16:59-66

24. Gissler M, Hemminki E, Louhiala P, Järvelin MR 1998 Health registers as a feasible means of measuring health status in childhood-a 7-year follow-up of the 1987 Finnish birth cohort. Paediatr Perinat Epidemiol 12:437-455

25. Gissler M 1999 Administrative Registers in Health Research - A Cohort Study of Finnish Children Born in 1987. In: STAKES (National Research and Development Centre for Welfare and Health), Helsinki 73

26. WHO 1977 Manual of the International Classification of Diseases, 9th Revision, Volumes 1 and 2. Geneva

27. Stewart AW, Asher MI, Clayton TO, Crane J, D'Souza W, Ellwood PE, Ford RP, Mitchell EA, Pattemore PK, Pearce N 1997 The effect of season-of-response to ISAAC questions about asthma, rhinitis and eczema in children. Int $\mathrm{J}$ Epidemiol 26:126-136

28. Sly RM 1997 New guidelines for diagnosis and management of asthma. Ann Allergy Asthma Immunol 78:427-437

29. von Mutius E, Martinez FD, Fritzsch C, Nicolai T, Reitmeir P, Thiemann HH 1994 Skin test reactivity and number of siblings. BMJ 308:692-695

30. Kulig M, Tacke U, Forster J, Edenharter G, Bergmann R, Lau S, Wahn V, Zepp F, Wahn U 1999 Serum IgE levels during the first 6 years of life. J Pediatr 134:453-458

31. Scolozzi R, Boccafogli A, Vicentini L, Baraldi A, Bagni B 1989 Correlation of MAST chemiluminescent assay (CLA) with RAST and skin prick tests for diagnosis of inhalant allergic disease. Ann Allergy 62:193a-193b

32. Sampson HA, Albergo R 1984 Comparison of results of skin tests, RAST, and double-blind, placebo-controlled food challenges in children with atopic dermatitis. J Allergy Clin Immunol 74:26-33

33. Remes ST, Korppi M, Remes K, Pekkanen J 1996 Prevalence of asthma at school age: a clinical population-based study in eastern Finland. Acta Paediatr 85:59-63

34. Burney PG, Chinn S, Rona RJ 1990 Has the prevalence of asthma increased in children? Evidence from the national study of health and growth 1973-86. BMJ 300:1306-1310

35. Robertson CF, Heycock E, Bishop J, Nolan T, Olinsky A, Phelan PD 1991 Prevalence of asthma in Melbourne schoolchildren: changes over 26 years. BMJ 302:1116-1118

36. Keskimaki I, Aro S 1991 Accuracy of data on diagnoses, procedures and accidents in the Finnish Hospital Discharge Register. Int J Health Sci 2:15-21

37. Perlow JH, Montgomery D, Morgan MA, Towers CV, Porto M 1992 Severity of asthma and perinatal outcome. Am J Obstet Gynecol 167:963-967 
38. Forastiere F, Agabiti N, Corbo GM, Dell'Orco V, Porta D, Pistelli R, Levenstein S, Perucci CA 1997 Socioeconomic status, number of siblings, and respiratory infections in early life as determinants of atopy in children. Epidemiology 8:566-570

39. Duran-Tauleria E, Rona RJ 1999 Geographical and socioeconomic variation in the prevalence of asthma symptoms in English and Scottish children. Thorax 54:476-481

40. Jana N, Vasishta K, Saha SC, Khunnu B 1995 Effect of bronchial asthma on the course of pregnancy, labour and perinatal outcome. J Obstet Gynaecol 21:227-232

41. Gregory A, Doull I, Pearce N, Cheng S, Leadbitter P, Holgate S, Beasley R 1999 The relationship between anthropometric measurements at birth: asthma and atopy in childhood. Clin Exp Allergy 29:330-333

42. Dashe JS, McIntire DD, Lucas MJ, Leveno KJ 2000 Effects of symmetric and asymmetric fetal growth on pregnancy outcomes. Obstet Gynecol 96:321-327

43. Lawoyin TO 1993 A prospective study on some factors which influence the delivery of large babies. J Trop Med Hyg 96:352-356

44. Saarinen UM, Kajosaari M 1995 Breastfeeding as prophylaxis against atopic disease: prospective follow- up study until 17 years old. Lancet 346:1065-1069
45. Oddy WH, Holt PG, Sly PD, Read AW, Landau LI, Stanley FJ, Kendall GE, Burton PR 1999 Association between breast feeding and asthma in 6 year old children: findings of a prospective birth cohort study. BMJ 319:815-819

46. Björksten B, Naaber P, Sepp E, Mikelsaar M 1999 The intestinal microflora in allergic Estonian and Swedish 2-year-old children. Clin Exp Allergy 29:342-346

47. Kalliomaki M, Kirjavainen P, Eerola E, Kero P, Salminen S, Isolauri E 2001 Distinct patterns of neonatal gut microflora in infants in whom atopy was and was not developing. J Allergy Clin Immunol 107:129-134

48. Gronlund MM, Arvilommi H, Kero P, Lehtonen OP, Isolauri E 2000 Importance of intestinal colonisation in the maturation of humoral immunity in early infancy: a prospective follow up study of healthy infants aged $0-6$ months. Arch Dis Child Fetal Neonatal Ed 83:F186-192

49. Chirico G, Gasparoni A, Ciardelli L, Martinotti L, Rondini G 1999 Leukocyte counts in relation to the method of delivery during the first five days of life. Biol Neonate 75:294-299

50. Pessi T, Sutas Y, Hurme M, Isolauri E 2000 Interleukin-10 generation in atopic children following oral Lactobacillus rhamnosus GG. Clin Exp Allergy 30:1804-1808 